\title{
On-line monitoring system applied to explosive conditions of printing machine dryers
}

\author{
J. Murčinko \& Z. Murčinková \\ Technical University of Košice, Faculty of Manufacturing Technologies \\ with seat in Prešov, Slovakia
}

\begin{abstract}
The paper deals with problems of the collision states monitoring in mass production process with potential environmental impact. The flexographic and rotogravure printing machines for plastic packaging flexible foils production are the objects of monitoring, mainly the drying technological sections. The paper is focused on the usage of vibration diagnostics of rotational equipment, i.e. ventilators in dryers. The selection of appropriate on-line system control by way of intelligent component implementation is a critical problem of mass production with dangerous operation. The project of monitoring system application is described. The new system of automatic monitoring regime with the use of artificial intelligence elements was projected and tested.

Keywords: emissions, bearing failure, envelope analysis, vibration monitoring.
\end{abstract}

\section{Introduction}

The producers invest a lot in upgrading and acquiring new machines and technologies, in particular in the field of film converting which allows to be flexible and to produce top-quality competitive products. The printing machines operate the latest flexoprinting and rotogravure technologies that meet demands of customers and also stringent legislative requirements for environmental protection.

The production of plastic flexible films is comprised in field of mass continuous production with the use of high-efficiency printing machines. The production of flexible plastic foils involves the eventual dangerous negative effects for the environment. It is a reason why we should pay considerable attention to the periodic modernisation of machine technological units and to use 
on-line control. The one of important printing machine technological sections is the drying section that uses the high-performance ventilators. The process monitoring is necessary for operating this equipment. The vibration automatic diagnostics of ventilators can minimize the unwanted impact on the environment.

\section{Printing machines}

The production machine, i.e. 8-colour (10-colour) flexographic or rotogravure printing machine (Fig. 1), consists of 8 (10) printing sections. The foil is wound off and traversed through printing sections between printing cylinders. The printing cylinder has an image carrier. Each printing section contains one ink colour. The combination of colours and images forms final printed graphic image. The printing speed is from 250 to $400 \mathrm{~m} / \mathrm{min}$ depending on the difficulty of image.

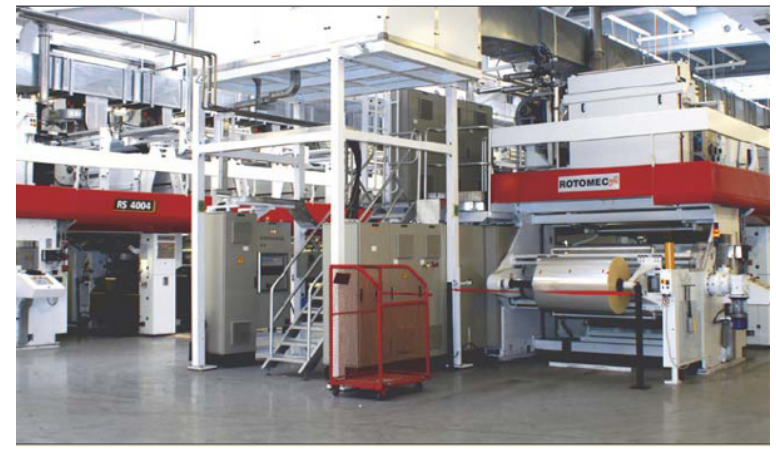

Figure 1: $\quad$ Printing machine and printing technologies.

Flexography (Fig. 1) is a printing process with image carrier on which the printing areas are above the non-printing areas. The used liquid inks are dried through the evaporation of organic solvents. The flexible packaging as bags, cartons, labels etc. are produced by the mentioned printing.

In rotogravure printing, the image area is engraved into the surface of image carrier (Fig. 1). The ink is picked up in the engraved area and ink is scraped off the non-image area. The image is pressed against the cylinder and then dried.

\subsection{Risk analysis of printing machines}

Failure Modes and Effects Analysis (FMEA) was used to analyze potential process failures in foil printing before they occur. FMEA evaluates potential failures of machine or equipment and their influence on technological process to eliminate or minimize the associated risk. The failure may occur in various levels, i.e. in main system, system, subsystem or in individual components. The 
mentioned method evaluates each component of system answering the following questions:

- What could go wrong?

- Why would the failure happen?

- What would be the consequences of each failure?

The success of FMEA depends on good forecast conception of failure reasons either the manufacturing process or manufacturing machine [1].

Having printed the foil by one ink colour, the ink of image is dried in dryer before entering the next section. Inks may contain different proportion of organic solvents and diluents. Printing can also require the use of cleaning solvents and organic dampeners. Inks, solvents, diluents, cleaners and dampeners make contribution to emissions that are sources of significant risk. The dangerous evaporated emissions introduce the risk for operating staff of plant as well as the environment. The dryer is a major risk source regarding to explosive conditions.

Fig. 2 shows the chain of failures that begin in component and propagate to whole technological machine. The curve illustrates dependency of time and costs spent either on component failure elimination or machine explosion.

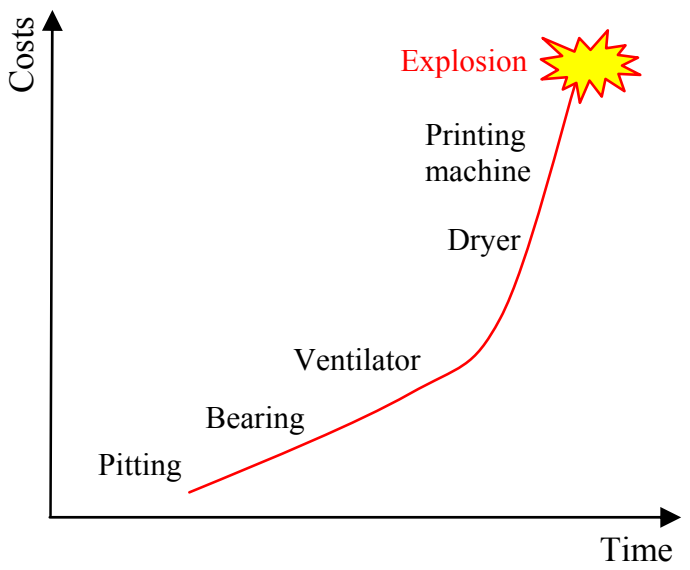

Figure 2: $\quad$ Costs spent on elimination of failure.

\subsubsection{The drying section}

The drying section comprises the groups of ventilators. Some printing machines have two drying sections (at the beginning and end) to achieve higher performance of drying. The part of dryer is in Fig. 3. The rotating ventilator wheel is fixed directly on output shaft of electromotor. Each ventilator of printing machine dryer is installed by such concept. The engine speed is regulated in dependence on demand of drying air.

The sensors in each section measure the emission concentration in air. In case of increased concentration, the revolutions of electromotor (ventilator) are increased up to maximum value, i.e. $5000 \mathrm{~min}^{-1}$. The diameter of ventilator wheel is $500 \mathrm{~mm}$; the electromotor power is up to $10 \mathrm{~kW}$. The operating environment of 


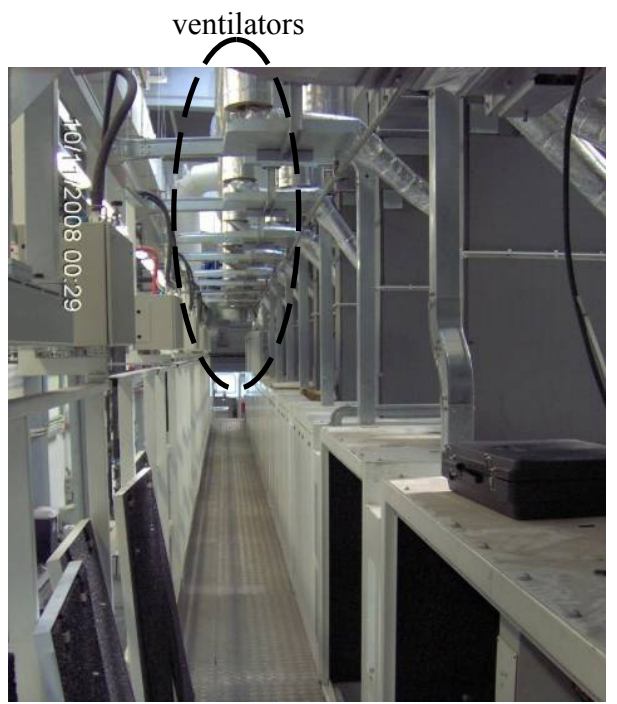

Figure 3: Drying section.

ventilators is explosive regarding to high concentration of emissions. The air is sent to combustion section where the emissions are burned.

The whole drying section is bounded by covering and the entrance to working ventilators is impossible. To repair the ventilators in case of fail or damage, the total shut down or decreasing of printing is necessary to do. The mentioned fact is not economical for production company.

The ventilator working conditions are evaluated according to fundamental defect frequencies (section 3.2). The bearing becomes the vibration exciter in terms of any fault of bearing components. The periodic frequencies of impact character are generated by passing the rolling elements through imperfections in contact surfaces (Fig. 6). The maximum values of contact stress are under contact surface of race and the un-wanted pitting appears. The computation and estimation of contact stresses are described in $[2,3]$.

\section{Sources of failures}

The most of specialists have opinion that more than $50 \%$ of all failures is caused by the misalignment. The machine parts (shafts, clutches and bearings) should be assembled without misalignment. Misalignment is often caused by uneven floor, thermal expansion, distortion due to fastening torque and improper mounting of coupling. There are two types of misalignment: angular and parallel (shown in Fig. 4) or their combination. The misalignment causes higher repeated bearing loading, than even permissible values, resulting in fatigue of bearings. The material fatigue is visible through the appearance of pitting.

The next source of failures may be the imbalance. The imbalance appears if the shaft axis of rotation is not the same as shaft geometric axis. The repeating forces are generated. 

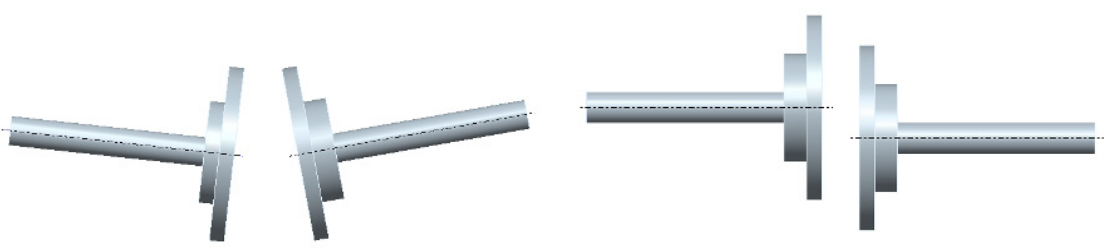

Figure 4: Angular and parallel misalignment.

Imbalance is caused by machining errors, non-uniform material density, missing balance weights, incorrect balancing, uneven motor winding, and broken, deformed, corroded or dirty blade tips. There are three types of the imbalance: static, moment and dynamic imbalance. The dynamic imbalance is combination of the first two types.

The only one force is acting in case of static imbalance. The word "static" means that such type of imbalance is visible in non-operating position. The moment imbalance (Fig. 5) is measurable only in operating phase. When the rotor is not working, it seems as balanced. During operating phase the two same forces (masses) are acting against each other. The described states cause rotor vibration and the values of measured phase on the two shaft ends are shift at $180^{\circ}$. The dynamic imbalance as combination of static and moment imbalance is the most occurring imbalance. The static imbalance is dominant for simple machines compared to complex machines (more than one clutch) with dominant moment imbalance.
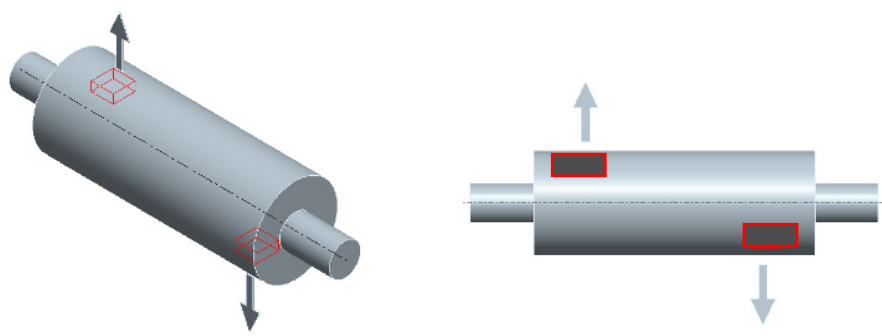

Figure 5: $\quad$ Moment imbalance.

To diagnose problems related to imbalance, the measurement of vibration, FFT spectrums and phases have to be done $[4,5]$. The vibration caused just by imbalanced have sinusoidal distribution with one wave per one revolution. The amplitudes for frequency of revolutions of FFT spectrum are higher. In ordinary, if the signal has harmonic multiple over the base frequency of revolutions then the problem is not caused by imbalance.

The other reasons for failures generated by the un-wanted vibration are, for example, mechanical unfastening, shaft bending, wrongly assembled bearing on the shaft. 


\subsection{Envelope analysis}

Applications of the rolling elements bearings and gear-mesh provide repetitive dynamic signal. If some damage appears, the signal is of impact type (especially with low-force impacts). Envelope analysis is a method that detects rotational defect signals of bearings and gearboxes. It allows early warning of developing damage. Envelope analysis is not suitable for non-impact type signals (e.g. for very large (stiff) machines) which generate only low-frequency signals.

The rolling element impacts the defect. The generated repetitive impulse depends on number of balls, bearing geometry, and defect location. The keystone of enveloping is to detect the bearing faults by capture (filter off) the low amplitude bearing defect signal with low energy without including the high amplitude rotational vibration signals. The low energy defect signal is lost in overall vibrations of shaft rotation.

The Hilbert transform technique is used for envelope analysis and signal processing. In digital signal processing, we often need to look at relationships between real and imaginary parts of a complex signal. These relationships are generally described by Hilbert transforms. Hilbert transform not only helps relate real and imaginary components but it is also used to create a special class of causal signals called analytic which are especially important in simulation. The analytic signals help us to represent band pass signals as complex signals which have special attractive properties for signal processing.

The Hilbert transform $H$ of function $x(t)$ is defined for all $t$ by:

$$
H\{x(t)\}=\widetilde{x}(t)=\frac{1}{\pi} \int_{-\infty}^{\infty} \frac{x(\tau)}{t-\tau} d \tau
$$

when the integral exists. It is normally not possible to calculate the Hilbert transform as an ordinary improper integral because of pole at $\tau=t$.

Hilbert transform enables calculation of envelope (magnitude) of time signal and allows definition of the analytical signal $x_{a}(t)$ from real-valued time signal as the real part $x(t)$ of the original time signal and imaginary part of the Hilbert transform:

$$
x_{a}(t)=x(t)+j \widetilde{x}(t)
$$

Envelope $A(t)$ of signal is numerical value of analytical signal:

$$
A(t)=\sqrt{x^{2}(t)+\tilde{x}^{2}(t)}
$$

\subsection{Bearing defects}

Bearing defects are generated by various reasons such as fatigue, poor installation, wear, improper lubrication or manufacturing faults. Spinning the bearing, the periodic frequencies are excited by the irregularities (e.g. microcracks) in the raceway surface or in roundness of rolling elements (Fig. 6, right). Fig. 6 (left) shows time record of envelope acceleration of damaged bearing.

The advantages of Envelope Acceleration Time record are the following: intensify useful signal for detection of failure or damage of bearing (or gear 

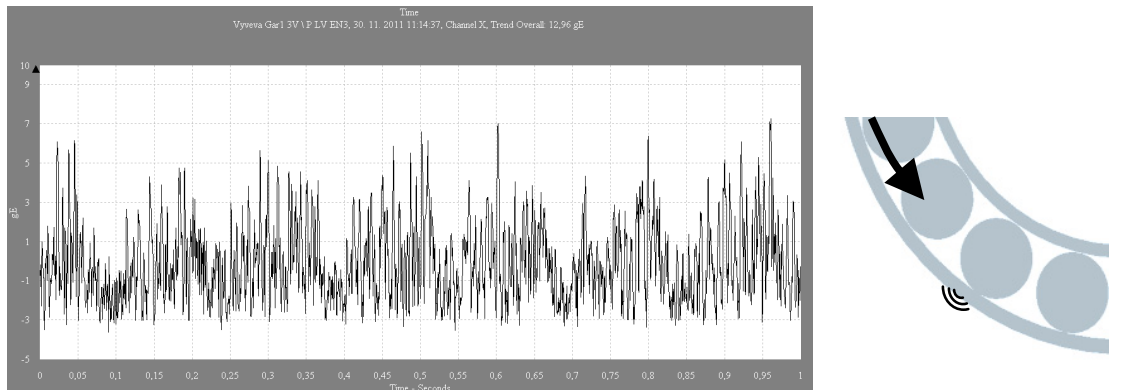

Figure 6: Envelope acceleration (left) and fault source (right).

mesh); reduce non-periodical signal and its noise; eliminate the low-frequencies and multiplies caused e.g. by electromotor frequency of revolutions [6].

To identify damaged bearing the FFT spectrums are needful to look over. Fig. 7 shows the FFT Spectrum of Envelope Acceleration. One dominant frequency $(131.5 \mathrm{~Hz})$ and multiplies $(263 \mathrm{~Hz}, 394 \mathrm{~Hz}, 526 \mathrm{~Hz})$ are visible. The dominant frequency is frequency of failed bearing. The bearing geometry and shaft revolutions influence the frequencies of defects. Mostly the bearing defect frequencies are provided by manufacturers or vibration analysis software that incorporates the database of them. Fundamental defect frequencies can be calculated as following:

- FTF - Fundamental Train Frequency - frequency of cage $f_{c}$ :

$$
f_{c}=\frac{1}{2} f_{o}\left(1-\frac{d_{g}}{D_{1}} \cos \alpha\right)
$$

- BSF - Ball Spin Frequency - circular frequency of each rolling element as it spins $f_{r e}$ :

$$
f_{r e}=\frac{1}{2} f_{o} \frac{D_{1}}{d_{g}}\left(1-\left(\frac{d_{g}}{D_{1}} \cos \alpha\right)^{2}\right)
$$

- BPFO - Ball Pass Frequency of Outer race - frequency created when all rolling elements roll across a defect in outer race $f_{\text {or }}$ :

$$
f_{\text {or }}=\frac{1}{2} f_{o} n_{g}\left(1-\frac{d_{g}}{D_{1}} \cos \alpha\right)
$$

- BPFI - Ball Pass Frequency of Inner race - frequency created when all the rolling elements roll across defect in the inner race $f_{i r}$ :

$$
f_{i r}=\frac{1}{2} f_{o} n_{g}\left(1+\frac{d_{g}}{D_{1}} \cos \alpha\right)
$$


where $f_{o}=n / 60$ is basic harmonic frequency, $n$ is shaft revolutions $\left[\mathrm{min}^{-1}\right]$, $\alpha$ is contact angle $\left[{ }^{\circ}\right], n_{g}$ is number of rolling elements, $D_{1}$ is pitch diameter $[\mathrm{mm}], d_{g}$ is ball diameter $[\mathrm{mm}]$.

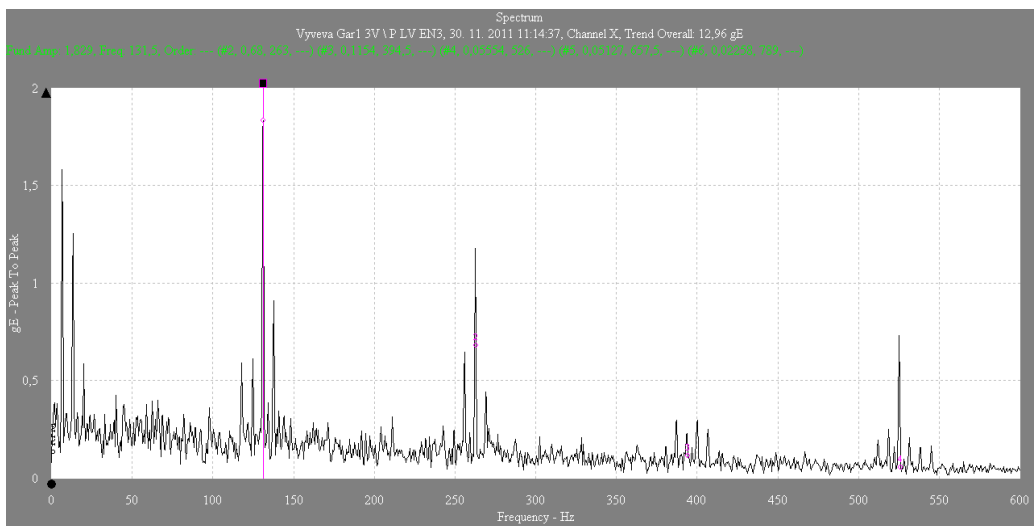

Figure 7: $\quad$ FFT Spectrum - damaged bearing.

\section{Monitoring system}

In order to design method and system of control, the vibrations was assigned as main dynamic parameter for determining the operating conditions of rotating ventilators.

The main aim of monitoring the vibrations of rotating machines parts is to provide the information about working and technical conditions of equipment in order to make strategic planning and maintenance management.

The vibration diagnostics is used as diagnostics of parameters of vibrations which are caused by machine dynamics. These diagnostics parameters give the
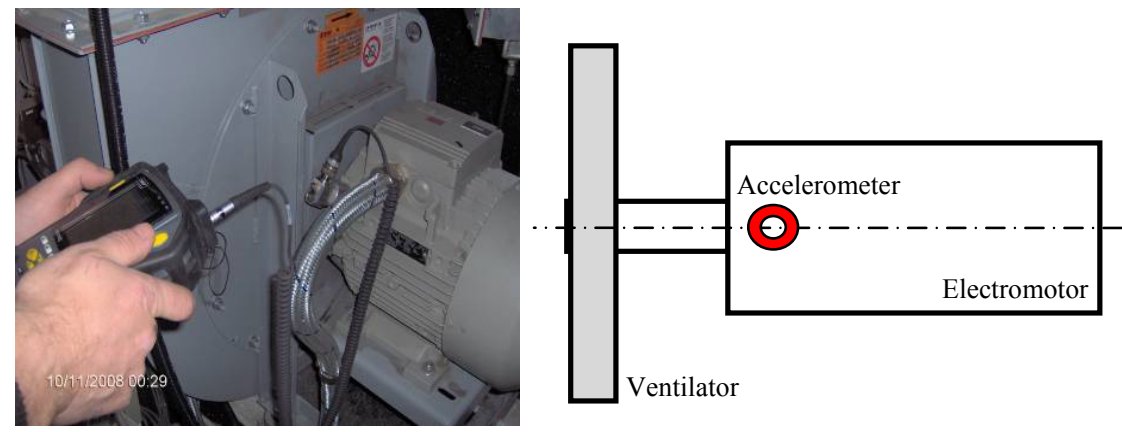

Figure 8: Electromotor position and position of sensor. 
information of objective technical condition estimation for rotating machines parts.

The experiences of previous patrol (off-line) system were involved in project. The mentioned previous system was un-able to detect fails and collision states in time. The vibration measuring was realized by system PXI (PCI eXtensions for Instrumentation - NI LabVIEW Order Analysis Toolkit, NI LabVIEW Sound and Vibration Toolkit). The vibration sensor MTN/1135C is accelerometer of small dimensions widely applied in industry, mainly for measuring vibrations of action members with rotation motion.

Fig. 9 shows the time record of envelope acceleration of good bearing. One can make a comparison with Fig. 6 . The significant difference in distribution is visible.

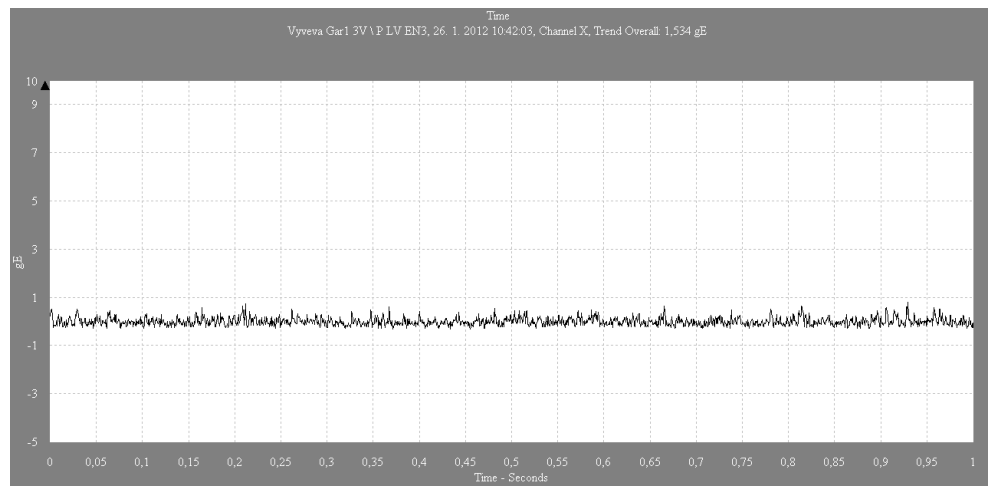

Figure 9: Time record of envelope acceleration - good bearing.

\subsection{Project of on-line monitoring system}

The continuous running of ventilators is suitable for regime of automatic control. The set of ventilators in dryer has important function of exhausting the explosive vapour that is a reason for continuous monitoring the working conditions of each ventilator. The find facts obviously confirm that implementation of on-line control systems for operating machines in mass production with environmental impact is needful.

The previous way of measuring, i.e. off-line control, was replaced by automated measuring system that significantly shortening time for elimination of failures. The aim is possible to achieve by early prediction of occurring problem. Further, the human factor in operating control is necessary to minimize regarding to explosive work conditions and high importance of drying section.

Involving the mentioned facts, the project was proposed. It utilizes software Lab View Professional Development System. The choice of hardware measuring components was influenced by present trends in field of artificial intelligence components development intended for explosive conditions [7-9].

The project of on-line monitoring system integrates knowledge in the field of artificial intelligence namely application the hardware and software for 
monitoring the process state and its evaluating. This new automatic system fully substitutes previous patrol system. The on-line monitoring system was projected with consulting of experts of diagnostics and technicians for printing machines.

The measuring system Oktalon was selected and implemented into designed measuring chain. The Oktalon system is modular multi-parameter measuring system for continuous monitoring of mechanical vibrations and diagnostics of roller bearings. The system is constructed on the base of neuron nets of LonWorks type with opened architecture. The measuring, evaluating and saving of measured values are realized in automatic regime. The measured values are compared with the set alarm levels.

Fig. 10 shows complex monitoring scheme with aid of Oktalon system. The status warning (yellow) and danger (red) are showed in colour. The output of measurement is on the LED panel through the software that is part of Oktalon system. The ventilators status can be checked by visual control of operating staff in central monitoring display.

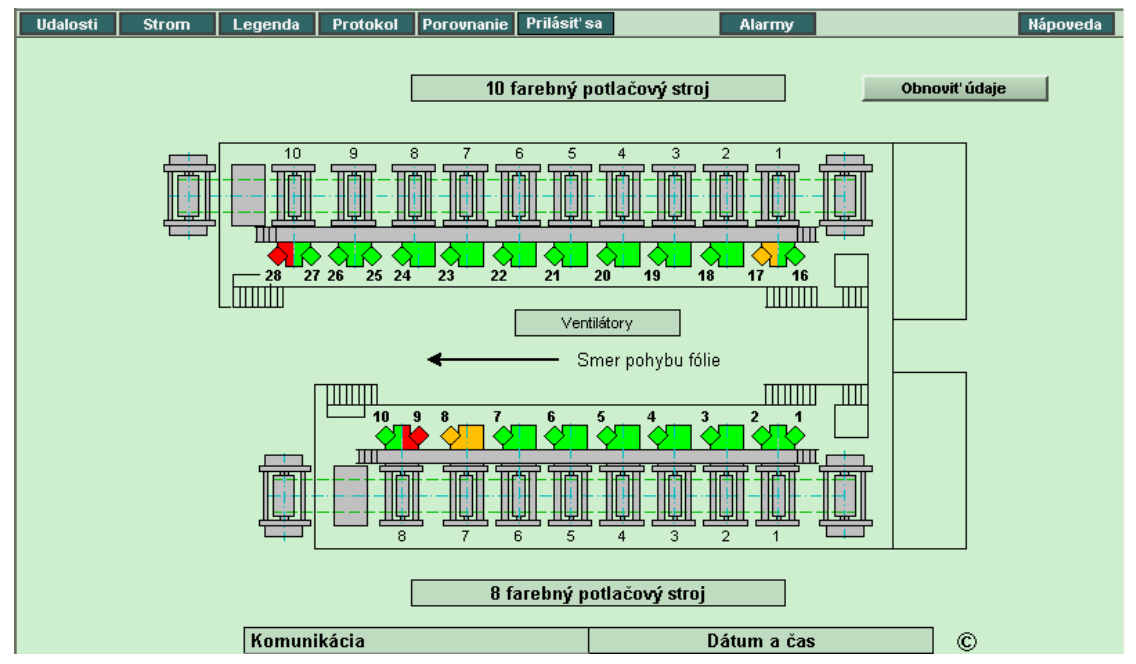

Figure 10: Monitoring scheme.

According to Vibration Severity Standard ISO 10 816-3 the limits of alarms are determined:

- values of Alarm 1 (Warning) are for vibration velocity $4.5 \mathrm{~mm} / \mathrm{s}$ and envelope acceleration $2.8 \mathrm{gE}$,

- values of Alarm 2 (Danger) are for vibration velocity $7.1 \mathrm{~mm} / \mathrm{s}$ and envelope acceleration $4.5 \mathrm{gE}$.

The potential statuses:

- In case that measured values are higher as the Alarm 1, it is necessary to check device (joint) or make the correcting operation. 
- In case that measured values are higher as the Alarm 2, the quality working is impossible to expect for a long period. The early repair is needful during the shutdown of the printing process.

\section{Conclusions}

The printing machine is complex technological machine consisting of several sections that have special functions. It was found that the drying section is the critical point for appearance of risk of explosion. The drying section involves groups of ventilators exhausting the dangerous emissions. The ventilator working conditions are projected not to develop the dangerous content of emissions. This fact denotes the ventilator as object of analysis since each of ventilators is the principal for safety operation. In case of collision in dryer, the required amount of dangerous exhalation could not be flow out into combustion section. It can cause the disaster with environmental impact. The enveloping method is described in paper as the most suitable method for analysis of running bearings (units).

The new system of automatic on-line monitoring regime with use of artificial intelligence elements that was projected and tested confirms the validity of purpose. The implementation of intelligence elements into on-line control eliminates human errors and furthermore it enables quality prediction of collisions. The effects are in field of economy (minimization of shut down of production due to failures) and in field of protection of environment. The following facts can be defined on the base of achieved results:

- The previous vibration diagnostics conditions of printing machines invite the innovation change with focus to automatic data collection, quick evaluation with required decision in case of failure.

- The new on-line system fulfils the request of failure-free automatic operation by reason of character of foil mass production where each unexpected production shut down is followed by large economy loss.

- The selection of monitoring components for automatic regime was built by use of artificial intelligence members for reason of specific technological conditions. The applied system allows so called 24-hours hot-line web service.

The main result of described project is on-line monitoring system designed for drying section and its achievements.

\section{Acknowledgement}

The authors would like to express their thanks for supporting this research by structural funds of EU grant with ITMS 26220220125 of the Agency of the Ministry of Education of the Slovak Republic.

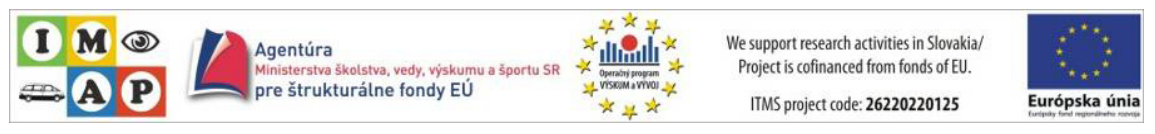




\section{References}

[1] Teoh, P. C., Case, K., Modelling and reasoning for failure modes and effects analysis generation. Proc. of the Institution of Mechanical Engineers, Part B: Journal of Engineering Manufacture, Loughborough University Mechanical and Manufacturing Engineering Loughborough, Leicestershire, UK, Vol. 218, no. 3, pp. 289-300, 2004.

[2] Murčinková, Z.: Softvérová lokalizácia maximálnych podpovrchových napätí pri bodovom kontakte 3D telies (Software localization of maximal subsurface stresses in point contact of 3D bodies). Proc. of VII. International scientific conference New ways in Manufacturing Technologies 2004, Technical University of Košice, Faculty of Manufacturing Technologies with seat in Prešov, pp. 468-471, 2004.

[3] Žmindák, M., Grajciar, I., Nozdrovický, J., Modelovanie a výpočty v metóde konečných prvkov (Modeling and computation in Finite Element Method), University of Žilina, Faculty of Mechanical Engineering, Žilina, 2004.

[4] Palm, J. W., Modeling, Analysis and Control of Dynamic Systems, $2^{\text {nd }}$ Ed., John Wiley \& Sons Inc., New York USA, 2000.

[5] Rilley, W. F., Johnston, J., Engineering Mechanics Dynamics, John Wiley \& Sons, Inc., New York, 1993.

[6] Kreidl, M., Šmíd, R., Technická diagnostika (Technical diagnostic), BEN, Prague, 2006.

[7] Jedináková, J., Baron, P., Kočiško, M., Created of the process plans in the context of ISO 9001. Machines, Technologies, Materials 2011: Scientific Proceedings: 8th international congress, Varna. Vol. 19, no. 6/126, pp. 164$165,2011$.

[8] Modrák, V., Paško, J., Pavlenko, S.: Alternative solution for a robotic stereotactic system, Journal of Intelligent and Robotic Systems: Theory and Applications, 35 (2), pp. 193-202, 2002.

[9] Vojtko, I., Mikita, J., Method of projecting modular structures for manufacturing technology. Annals of DAAAM for 2011 \& Proceedings of the $22^{\text {nd }}$ International DAAAM Symposium on "Intelligent Manufacturing \& Automation", Vienna, pp. 263-264, 2011. 